\title{
URBAN TRAFFIC AND AIR QUALITY EVOLUTION UNDER ECONOMIC RECESSION CONDITIONS
}

\author{
NIKOLAOU $\mathrm{K}^{1, *}$ \\ BASBAS S. ${ }^{2}$
}

${ }^{1}$ Organization for the Master Plan and Environmental Protection of Thessaloniki 105 Vas. Olgas Str., 54643 Thessaloniki, Greece

${ }^{2}$ Dept. of Transportation \& Hydraulic Engineering Faculty of Rural \& Surveying Engineering, School of Engineering Aristotle University of Thessaloniki, 54124 Thessaloniki, Greece
Received: 10/10/2012

Accepted: 01/10/2014

Available online: 02/10/2014 *to whom all correspondence should be addressed: e-mail: kinikola@hol.gr

\section{ABSTRACT}

This paper deals with the impacts of the current economic crisis on the temporal variation of urban traffic (during 2008-11) and consequently, the impacts on the urban air pollutant levels using as case study the city of Thessaloniki, Greece.

The important temporal variations of the main economic indicators like the annual decreasing trend of the gross domestic product (GDP), the continuous decrease of wages and the labor cost index, the annual increase of unemployment and hence, the decreasing trend of consumption and domestic demand during the current recession period in Greece affect the vehicle traffic.

A considerable decreasing trend of vehicle traffic volume has been observed in all examined intersections of Thessaloniki urban area. The highest temporal decrease of traffic volume is occurred in the morning hours.

The traffic volume decrease determines decisively the concentrations of urban air pollutants and especially, the concentrations of $\mathrm{NO}_{2}$ (nitrogen dioxide), which has mainly traffic emissions origin and the concentrations of PM10 (suspended particulate matter with aerodynamic diameter less than 10 $\mu \mathrm{m})$, which has mainly diesel cars emissions origin.

The correlation between traffic and air pollution decreasing trend shows that the air pollutant concentrations decrease is more significant in relation to the traffic decrease due to the fact that, even a small traffic decrease leads to a significant amelioration of the traffic conditions, which lead to significant lower car emissions and therefore, to significant lower pollutant concentrations in the air of the urban area.

The economic crisis did not lead to an increase of the public transport use. It seems that, the traffic decrease of the passenger cars and taxis is due to the trips decrease because of unemployment, the trips decrease connected to lost work positions and the elastic importance trips decrease (shopping, entertainment, etc) during 2008-11.

Keywords: air pollution, traffic, urban area, economic recession

\section{Introduction}

The current economic crisis affected all sectors of production and consumption having important environmental impacts. On one hand, the decline in production and consumption could lead to a lower 
level of air pollution. On the other hand, the problem of pollution may become worse during the crisis period because the environmental protection could have a lower priority (Barbu, 2010).

The structural change in industries in combination with the severity of the crisis is expected to affect the medium term development pathway of emissions. A possible severe slowdown in environmental investments and environmental research and development will lead to serious long-term environmental impacts (Berghäll and Perrels, 2010). The efforts to ameliorate environmental decline will prove very expensive and out of reach for already-stretched budgets. The question thus arises: Will the crisis be good or bad for the environment, especially with respect to air pollutant emissions? (Klare, 2008).

Given the fact that the actual phase of the economic crisis affects simultaneously the society, economy and environmental protection, i.e. all the sectors of sustainability, a systematic approach of the current situation is necessary (Nikolaou, 2011).

This paper deals with the impacts of the current economic crisis on the temporal variation of urban traffic (during 2008-11) and consequently, the impacts on the urban air pollutant levels using as case study the city of Thessaloniki, Greece.

\section{Methodology}

The traffic and air pollutant concentrations data have been collected during the period 2008-11 in Thessaloniki urban area.

Traffic data include measurements of traffic volume (expressed in pcu: passenger car units) in four important intersections of Thessaloniki urban area: 1) B. Olgas - M. Mpotsari, 2) B. Olgas - 25hs Martiou, 3) Papandreou - 25hs Martiou and 4) Papandreou - Th. Sofouli. The B. Olgas street is one of the main entrances from the east part of Thessaloniki area to the city centre and the Papandreou street is one of the main exits from the centre to the east part of Thessaloniki area.

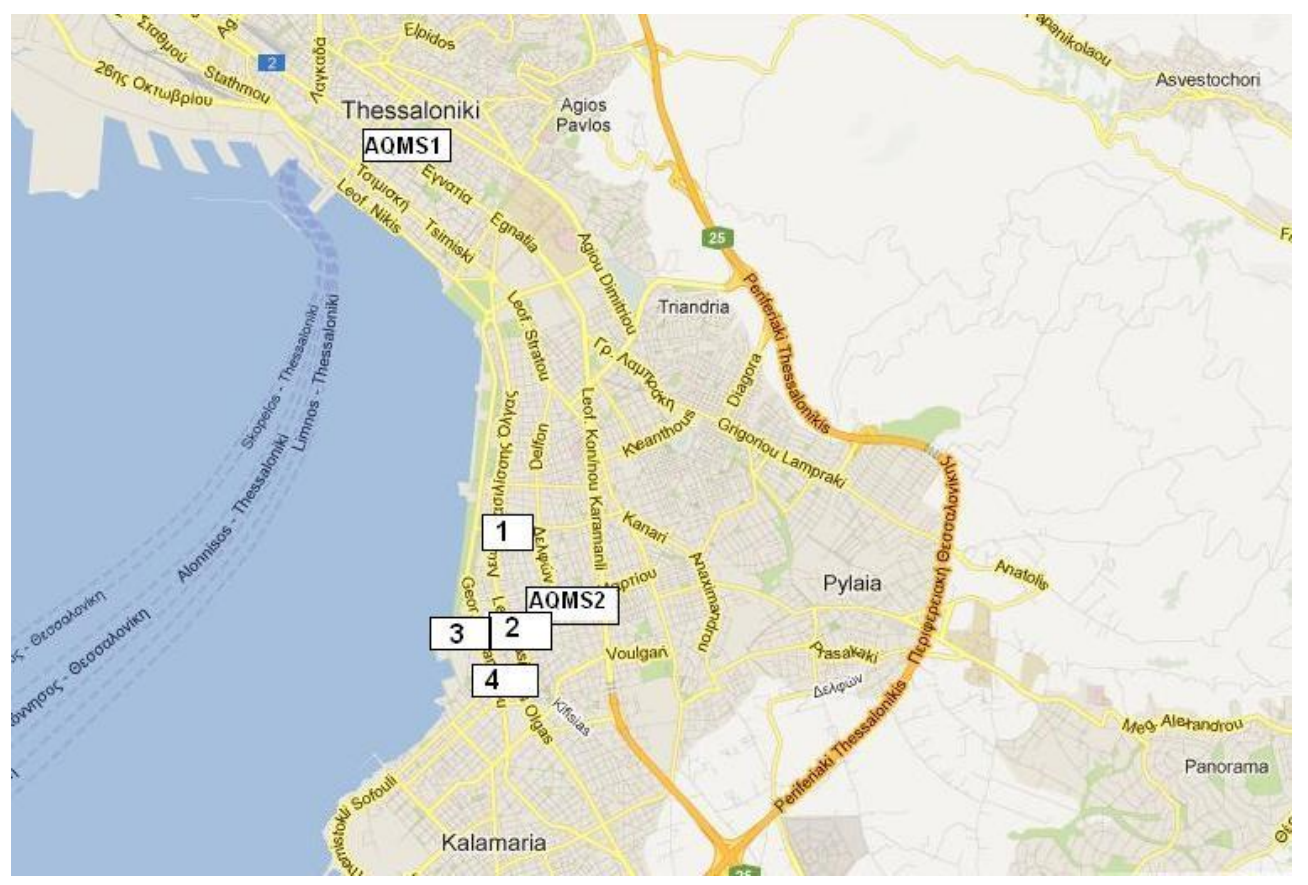

Picture 1. The locations of the air quality monitoring stations AQMS1 (city centre), AQMS2 (east urban area) of Thessaloniki and the traffic data intersections: 1) B. Olgas - M. Mpotsari, 2) B. Olgas - 25hs Martiou, 3) Papandreou - 25hs Martiou and 4) Papandreou - Th. Sofouli

The air pollutant concentration data resulted from two air quality monitoring stations: the one is located in the city centre (Egnatia) and the other in the east urban area (Martiou). The stations record 
continuously measurements of the pollutant concentrations during 24 hours and they are operated by the Environmental Department of the Municipality of Thessaloniki (MoTh, 2012). The pollutants considered are nitrogen dioxide $\left(\mathrm{NO}_{2}\right)$ and suspended particulate matter (PM10), which are strongly related to the traffic in the urban area (Nikolaou, 2002; Nikolaou et al., 2004; Terzi et al., 2010).

\section{Results and discussion}

The important temporal variations of the main economic indicators like the annual decreasing trend of the gross domestic product (GDP), the continuous decrease of wages and the labor cost index, the annual increase of unemployment and hence, the decreasing trend of consumption and domestic demand during the current recession period in Greece (ELSTAT, 2011) affect the vehicle traffic, as it is resulted by the decreasing trend of gasoline and diesel consumption recorded in Greece according to data of the Ministry of Environment, Energy and Climate Change.

A considerable decreasing trend of vehicle traffic volume (in passenger car units: pcu) has been observed in all examined intersections of Thessaloniki urban area during 2008-11 (Figure 1). The traffic volume decrease in the intersections: B. Olgas - M. Mpotsari, Papandreou - Th. Sofouli and Papandreou $25 \mathrm{hs}$ Martiou is $24 \%, 18 \%$ and $11 \%$ respectively.

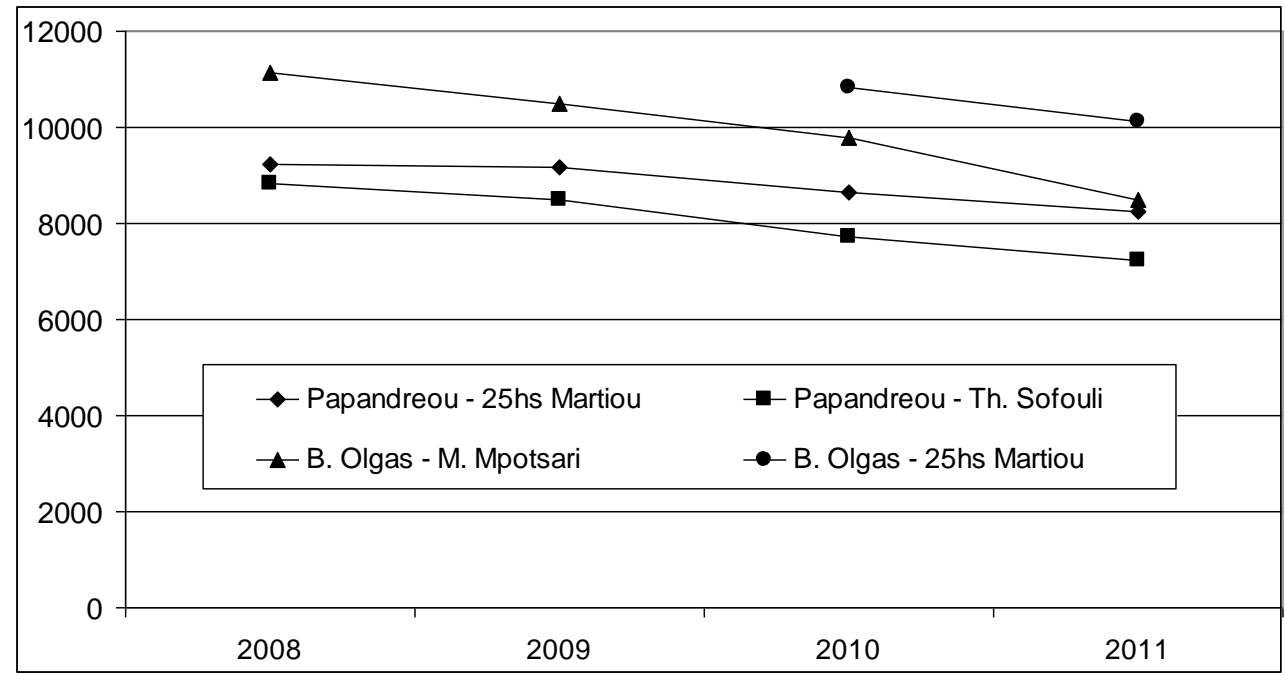

Figure 1. Temporal variation of vehicle traffic volume (in passenger car units: pcu) in four intersections of Thessaloniki urban area during 2008-11

By placing focus on the B. Olgas street (which is one of the main entrances from the east part of Thessaloniki area to the city centre) and especially on the B. Olgas - M. Mpotsari intersection, it is observed that the highest temporal decrease (33\%) of traffic volume is occurred in the morning hours 09:00-10:00 (Figure 2), while for the hours 10:00-11:00, 13:00-14:00 and 14:00-15:00, the traffic volume temporal decrease is $21 \%, 23 \%$ and $19 \%$ respectively.

Similarly, by studying the Papandreou street (which is one of the main exits from the centre to the east part of Thessaloniki area) and especially the Papandreou - 25hs Martiou intersection, it is observed that the highest temporal decrease (17\%) of traffic volume is occurred in the morning hours 09:00-10:00 (Figure 3), while for the hours 10:00-11:00, 13:00-14:00 and 14:00-15:00, the traffic volume temporal decrease is $13 \%, 2 \%$ and $11 \%$ respectively.

It is well known that peak hour, as traffic is concerned, is not the same among the different days of a week. Peak hour is affected by a number of factors (e.g. the opening time of the market etc) and thus, it is not necessarily appeared during the early morning hours. In the case of the paper, peak hour is observed after 10:00. 


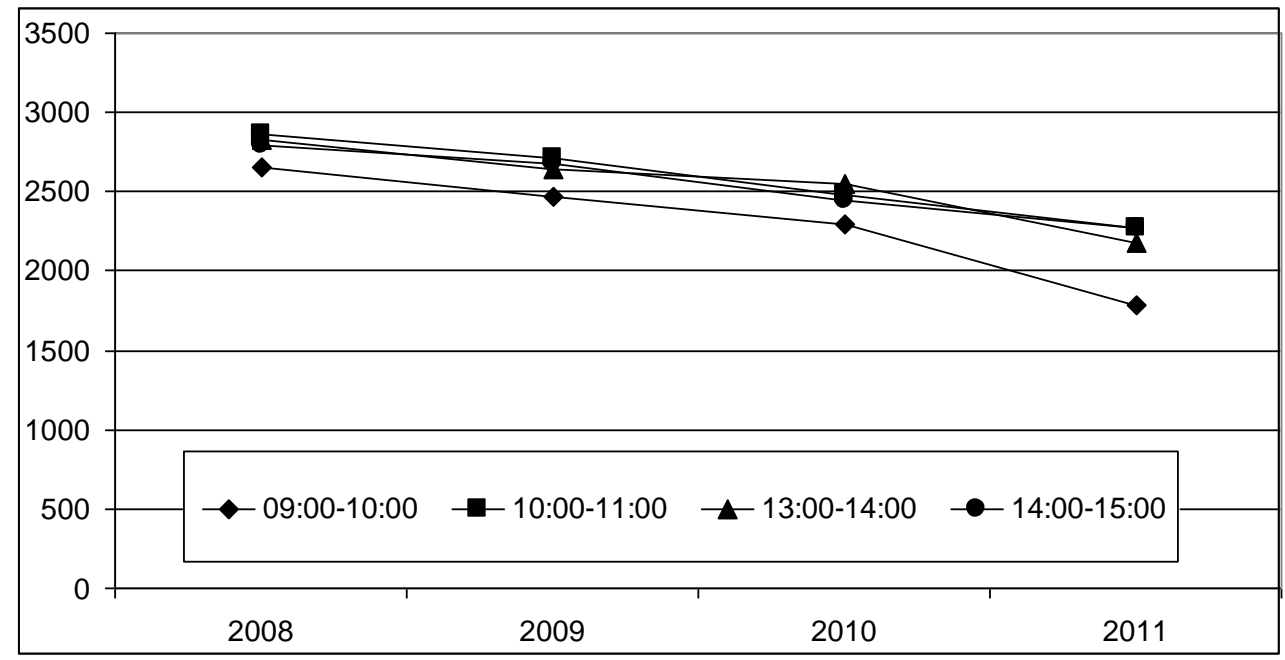

Figure 2. Temporal variation of morning and afternoon vehicle traffic volume (in passenger car units: pcu) in the B. Olgas-M. Mpotsari intersection of Thessaloniki urban area during 2008-11

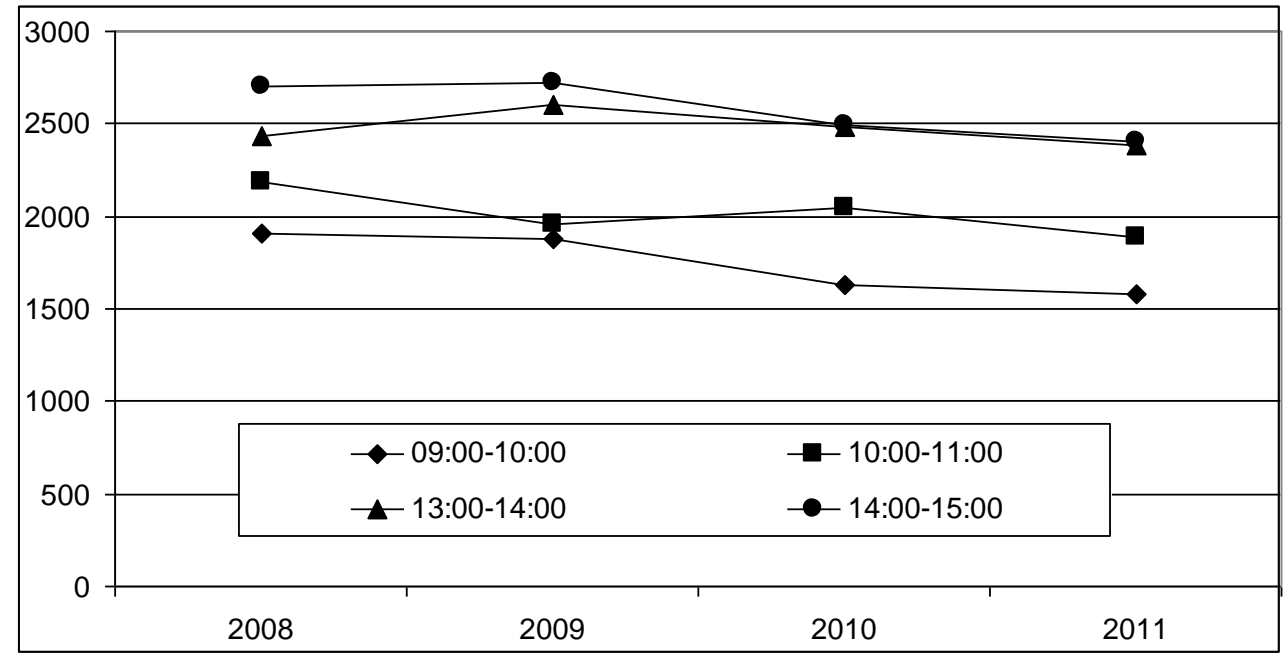

Figure 3. Temporal variation of morning and afternoon vehicle traffic volume (in passenger car units: pcu) in the Papandreou-25hs Martiou intersection of Thessaloniki urban area during 2008-11

The considerable decrease of vehicle traffic volume (24\%) observed in B. Olgas street (B. Olgas - M. Mpotsari intersection) determines the traffic volume decrease in the city centre because this is one of the main entrances from the east part of Thessaloniki area to the city centre. The traffic decrease in the city centre has been also confirmed in previous studies, where the diurnal variation of passenger cars traffic and taxi traffic has been studied during the recession period (Nikolaou et al., 2011; Ntoumanakis and Nikolaou, 2011).

Also, the higher temporal decrease (33\%) of traffic volume recorded in the morning hours 09:00-10:00 in the B. Olgas - M. Mpotsari intersection, is very important for the levels of air pollution, because it coincides with the morning maximum of air pollutant concentrations, which is determinant for the daily and annual pollution levels.

The traffic volume decrease determines decisively the concentrations of urban air pollutants and especially, the concentrations of $\mathrm{NO}_{2}$ (nitrogen dioxide), which has mainly traffic emissions origin and the concentrations of PM10 (suspended particulate matter with aerodynamic diameter less than 10 $\mu \mathrm{m})$, which has mainly diesel cars emissions origin. There is a special interest for $\mathrm{NO}_{2}$ and $\mathrm{PM} 10$ because their levels are usually above the air quality standards in Thessaloniki and many other European cities. 
A considerable decreasing trend of the number of days with PM10 daily average concentrations over 50 $\mu \mathrm{g} \mathrm{m}^{-3}$ (24 hours average limit), has been observed in the city centre (Egnatia) and east part (25hs Martiou) of Thessaloniki urban area during 2008-10 (Figure 4). The decrease of the PM10 over limit days is $59 \%$ and $44 \%$ in the city centre and east part respectively and it is remarkably higher than the decrease of the PM10 annual average concentrations, which is $26 \%$ and $25 \%$ in the city centre (from $62,4 \mathrm{mg} \mathrm{m}^{-3}$ in 2008 to $46 \mu \mathrm{g} \mathrm{m}^{-3}$ in 2010) and east part (from $41,5 \mathrm{\mu g} \mathrm{m}^{-3}$ in 2008 to $31 \mathrm{\mu g} \mathrm{m}^{-3}$ in 2010) respectively. These results show that the decreasing trend of traffic (especially the traffic of diesel engine equipped taxis, which is a very important PM10 emission source in the urban area) leads to considerably fewer PM10 "episode" days.

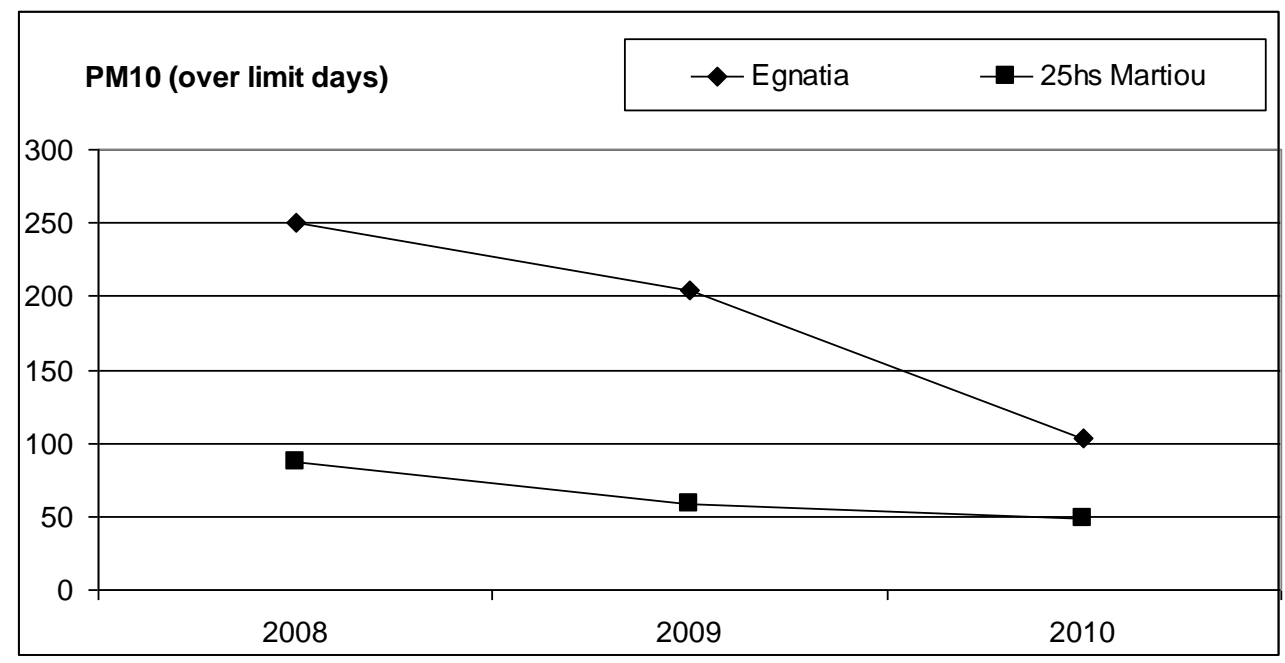

Figure 4. Temporal variation of the number of days with PM10 daily average concentrations over 50 $\mathrm{\mu g} / \mathrm{m}^{3}$ (24 hours average limit), in the city centre (Egnatia) and east part (25hs Martiou) of Thessaloniki urban area during 2008-10

The decrease of the $\mathrm{NO}_{2}$ annual average concentrations is $5 \%$ and $25 \%$ in the city centre (Egnatia) and east part (25hs Martiou) of Thessaloniki urban area during 2008-10 (Figure 5), while the decrease of the $\mathrm{NO}_{2}$ over limit days (days with $\mathrm{NO}_{2}$ hourly concentrations over $200 \mu \mathrm{g} \mathrm{m}^{-3}$ ) is $91 \%$ in the city centre. The decreasing trend of traffic leads also to considerably lower $\mathrm{NO}_{2}$ levels.

It is well known that, the concentrations of $\mathrm{NO}_{2}$ have two origins in the urban air: 1) a direct $\mathrm{NO}_{2}$ vehicle emission, which is the minor portion and 2) a photochemical transformation of NO, which is also emitted mainly from vehicles (industrial and domestic heating emissions have a small contribution to NOx concentrations in the city centre air), which is the major portion. Consequently, the $\mathrm{NO}_{2}$ concentrations in the urban air, directly and indirectly (after photochemical transformation) are due mainly to the traffic. Given the fact, that there is no important change of the solar radiation during the examined crisis period, the recorded $\mathrm{NO}_{2}$ variation is due mainly to the traffic variation. Of course, the $\mathrm{NO}_{2}$ temporal variation is not linearly related to the traffic temporal variation (because it is a secondary pollutant) as it is happened for the primary pollutants. But ultimately, the main reason for the observed decrease of $\mathrm{NO}_{2}$ concentrations during the crisis period is the traffic volume decrease.

The air pollutant annual average concentrations and the over limit days is an important indicator of the indicators system for sustainability and environment in the urban area (OSET, 2012; Moussiopoulos et al., 2010). Thus, the observed decrease of $\mathrm{NO}_{2}$ and $\mathrm{PM} 10$ levels influences positively the evolution of this indicator.

The correlation between traffic and air pollution decreasing trend shows that the air pollutant concentrations decrease is more significant in relation to the traffic decrease due to the fact that, even a small traffic decrease leads to a significant amelioration of the traffic conditions, which lead to 
significant lower car emissions and therefore, to significant lower pollutant concentrations in the air of the urban area.

Under normal conditions, the traffic decrease leads to an increase of the public transport use, but not any significant use increase of public transport has been observed in Thessaloniki during the recession period. The same phenomenon has been observed in Athens and in other European cities like London, Paris, Milan, Madrid, Barcelona, where the public transport passengers have been decreased during the recession period (Karlaftis, 2010).

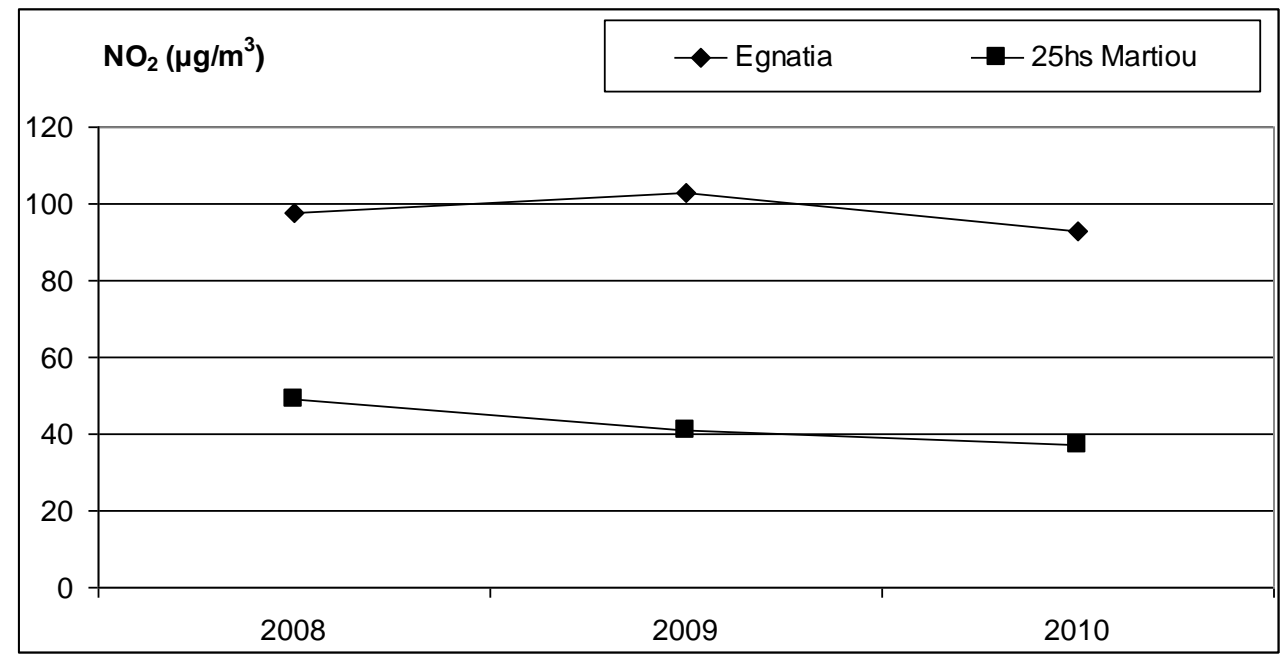

Figure 5. Temporal variation of the $\mathrm{NO}_{2}$ annual average concentrations in the city centre (Egnatia) and east part (25hs Martiou) of Thessaloniki urban area during 2008-10

The economic crisis did not lead to an increase of the public transport use. It seems that, the traffic decrease of the passenger cars and taxis is due to the trips decrease because of unemployment, the trips decrease connected to lost work positions and the elastic importance trips decrease (shopping, entertainment, etc) during 2008-11. Therefore, it can be assumed that mobility is highly affected by the economic crisis.

The provisionally observed urban air pollution decrease could create an illusion that the economic crisis has positive impacts on the urban air quality. But, all the economic indicators variation mentioned above could lead soon in another phenomenon: the insufficient maintenance of vehicles because of low incomes. It is well known that, even a small percentage (10-20\%) of insufficiently maintained vehicles could be responsible for the half of the urban air pollution (Nikolaou and Stedman, 1993; Nikolaou et al., 1994). In this case, even an important traffic decrease could be accompanied by an urban air pollution levels increase. That it was happened during 1990-95 in Greece, when the air pollution levels were higher, while there was the half traffic in relation to the current period.

\section{Conclusions}

A considerable decreasing trend of vehicle traffic volume has been observed in all examined intersections of Thessaloniki urban area during the current economic crisis period (2008-11). The highest temporal decrease of traffic volume is occurred in the morning hours.

The traffic volume decrease determines decisively the concentrations of urban air pollutants and especially, the concentrations of $\mathrm{NO}_{2}$, which has mainly traffic emissions origin and the concentrations of PM10, which has mainly diesel cars emissions origin.

The correlation between traffic and air pollution decreasing trend shows that the air pollutant concentrations decrease is more significant in relation to the traffic decrease due to the fact that, even a 
small traffic decrease leads to a significant amelioration of the traffic conditions, which lead to significant lower car emissions and therefore, to significant lower pollutant concentrations in the air of the urban area.

The economic crisis did not lead to an increase of the public transport use. It seems that, the traffic decrease of the passenger cars and taxis is due to the trips decrease because of unemployment, the trips decrease connected to lost work positions and the elastic importance trips decrease (shopping, entertainment, etc) during 2008-11.

\section{REFERENCES}

Barbu C. (2010), How the economic crisis affects the environment?, Journal of Environmental Management and Tourism, I(2), 85-91.

Berghäll E. and Perrels A. (2010) The economic crisis and its consequences for the environment and environmental policy, Nordic Council of Ministers, Copenhagen.

ELSTAT (2011) The Greek Economy, Hellenic Statistical Authority, Athens, Greece.

Karlaftis M. (2010), The economic crisis, the trips and the future of the mass transport, Bulletin of the Transport Engineers Greek Association, 174, 2-5.

Klare M.T. (2008), The economic crisis and the environment, The Huffington Post, 17 October 2008.

MoTh (2012) Air pollution data archives, Environmental Department of the Municipality of Thessaloniki, Thessaloniki, Greece, http://www.envdimosthes.gr, (accessed February 10, 2012).

Moussiopoulos N., Achillas Ch., Vlachokostas Ch., Spyridi D. and Nikolaou K. (2010), Environmental, social and economic information management for the evaluation of sustainability in urban areas: A system of indicators for Thessaloniki, Greece, Cities, 27(5), 377-384.

Nikolaou K. (2002), Comparative evaluation of the air quality in Athens and Thessaloniki versus EC new standards, Fresenius Environmental Bulletin, 11(8), 426-431.

Nikolaou K. (2011), Science and crisis: Approaching the socially equitable exit, Proceedings of the $21^{\text {st }}$ Hellenic Congress of Chemistry, Thessaloniki, Greece, 2011.

Nikolaou K. and Stedman D. (1993), Remote sensing of vehicle emissions. Case study: Thessaloniki-Greece, Proceedings of the 4th International Conference on Advances in Communication and Control, Rhodes, Greece, 1993, pp. 80-86.

Nikolaou K., Stedman D., Papaioannou S., Zoumakis N. and Kelesis A. (1994), Determination of parameters influencing the vehicle emissions in Greece, using a remote sensing system, Actes INRETS, 37, 160-165.

Nikolaou K., Basbas S. and Taxiltaris C. (2004), Assessment of air pollution indicators in an urban area using the DPSIR model, Fresenius Environmental Bulletin, 13(9), 820-830.

Nikolaou K., Ntoumanakis E., Basbas S. and Stamos I. (2011), Diurnal urban traffic and air quality during 2009-11 in Thessaloniki, $16^{\text {th }}$ International Symposium on Environmental Pollution and its Impact on Life in the Mediterranean Region, MESAEP, Ioannina, Greece, 2011

Ntoumanakis E. and Nikolaou K. (2011) Air pollutant variation in correlation to the traffic and meteorological conditions in Thessaloniki city, Proceedings of the $4^{\text {th }}$ Environmental Conference of Macedonia, Thessaloniki, Greece, 2011.

OSET (2012) Observatory for Sustainability and Environment in Thessaloniki, http://www.oset.gr, (accessed February 10, 2012).

Terzi E., Argyropoulos G., Bougatioti A., Mihalopoulos N., Nikolaou K. and Samara C. (2010), Chemical composition and mass closure of ambient PM10 at urban sites, Atmospheric Environment, 44(18), 2231-2239. 